\title{
Circular Economy: Global Experience and Practical Aspects of Implementation in Ukraine
}

\author{
Yaroslav Kotlyarevskyy ${ }^{*}$ [0000-0003-3542-6952], Andriy Shtangret 2 [0000-0001-5179-4996], \\ Alexandr Melnikov 3 [0000-0002-9741-9726]
}

\author{
${ }^{1}$ Ministry of Finance of Ukraine, Kyiv, Ukraine \\ ${ }^{2}$ Ukrainian Academy of Printing, Kyiv, Ukraine \\ ${ }^{3}$ IT STEP University, Kyiv, Ukraine \\ *econexpert@ukr.net
}

\begin{abstract}
Further application of the 'linear' model of the economy with trends towards an increase in the world's population and high rates of extraction of natural resources exacerbates the problem of human survival in the short term. The circular economy as a significantly different model is focused not only on reducing the consumption of natural resources, but also on using them more efficiently in the longer term, recycling and reduction of waste, which generally makes it possible to achieve the Sustainable Development Goals. The most developed countries of the world and the EU Member States have already gained the necessary experience in applying the basic principles of circular economics, which allow not only to improve the environmental situation but also ensure high economic efficiency in implementing measures at interrelated levels (national, corporate, personal). Ukraine develops strategies for broader implementation of the circular economy principles, while lagging behind other countries. The analytical study is aimed at identifying key problems that need to be addressed in order to reduce the gap in the development of the circular economy.
\end{abstract}

Keywords: circular economy, waste, recycling, resources, reuse.

\section{FOREWORD}

The idea of a circular economy is not new, it was gradually formed under the influence of the realization that the resources of our planet are not unlimited, and the growing rate of their use brings humanity closer to disaster. The work of K. Boulding titled "Economics of the future spacecraft Earth" (1966) [1] can be regarded as the basis for the development of the concept of circular economy. Later, the idea of K. Boulding was used by D.Pierce and K.Turner, who in their treatise "Economics of Natural Resources and Environment" (1992) [2; 3] substantiated the basic principles of circular economics. Rather succinctly, the main stages of changing approaches to the interpretation of the principles of circular economics were formulated by the Polish scientist I. Kulczycka: at first, it "concerned mainly waste management, then minimizing the consumption of resources, including energy, and then using waste as resources" [4].

It is advisable to recognize that at the first stages in the interpretation of the circular economy, the main attention was paid to environmental issues. Only later did the discussion about the economic value developed, which began to be seen in the possibility of improving the competitiveness of products by reusing a certain part of materials, which requires the use of the latest innovative technologies. Thus, the significant economic progress of the PRC over the last decade is directly related to the results of forming the circular economy, where since 2005 the implementation of the national strategy for the circular economy began in order to reduce resource and energy intensity through reduction, reuse and processing, which was based on a high level of innovation [5], which provides for the development of more environmentally friendly and competitive production. The high efficiency of the implementation of this strategy is evidenced by the fact that in 2006-2010 the energy intensity of the Chinese economy was reduced by $20 \%$ [6]. In 2013, the China Association of Circular Economy was established whose main task is to coordinate actions in applying the principles [7] of circular economy at the national level, at the level of individual producers and the actions of each individual citizen in the process of consumption or use of products (services). 
The issue of low competitiveness of products not only in the foreign but also the domestic market is extremely acute for the national economy of Ukraine including due to limited resources and critically high material and energy intensity of production. Accordingly, there are grounds to assert that the transition to a circular model of the economy, based on the study of the best foreign experience [8] and taking into account the peculiarities of the national economic environment, is critical, and therefore requires the establishment of an appropriate theoretical basis.

\section{RESEARCH METHODOLOGY}

The modern interpretation of the circular economy was formed by a certain combination of a number of concepts, among which we can distinguish Cradle-toCradle [9]; Industrial Ecology [10], Blue Economy [11] and Biosphere Rules [12].

C. Demin interprets the circular economy as "a kind of template of economic exploitation, where material resources can be used in a circle, that is, including reproduction. The goal of the circular economy is to ensure the infinite use of material resources" [13].

In accordance with this definition, in 2015 the Ellen MacArthur Foundation's analysts formulated the following principles of circular economy: preserve and multiply natural capital by managing limited reserves and balancing the flow of renewable resources; optimize resource extraction through the circulation of products, components and materials with the highest utility throughout time at all stages in both technical and biological cycles; promote systems efficiency by identifying negative external factors and further redesign of production activities [14].

In Ukraine, the focus on the transition to a circular economy is specified in the Presidential Decree "Sustainable Development Goals 2030", where, in accordance with the UN General Assembly Resolution No. 70/1 of 25.09.2015 and the results of their adaptation in the national report "Sustainable Development Goals: Ukraine", the twelfth goal is defined as "ensuring the transition to rational consumption and production models' [15]. In addition, the Low-carbon Development Strategy of Ukraine 2050 was adopted [16], which declared the implementation of environmentally safe production and the use of "green" technologies in all sectors of the national economy. The same Strategy defines the reuse of oil refining waste, mine methane, and biomass waste incineration at power plants in accordance with the principles of a circular economy.

To summarize the global experience and analyze the actual steps taken to implement the circular economy model in Ukraine, the following methods are used: induction and deduction, comparison and systematization - when studying the essential characteristics of the term "circular economy"; synthesis and analysis — when comparing the cyclic economy practice in the most developed countries of the world and the EU countries and in Ukraine; abstract-logical — for theoretical generalizations and research conclusions.

\section{RESEARCH RESULTS}

The circular economy is based on the design of a product taking into account its longest possible life cycle subject to high durability, possibility of repair, modernization, use for other purposes with subsequent processing to obtain resources as the basis for creating new products with minimal involvement of additional resources. Given such conditions, products necessary for humans are manufactured on the basis of the awareness of limited resources, that is, with minimal interference with the current level of balance between society and nature. Minimal changes in this balance should be achieved by reducing the extraction of natural resources and disseminating renewable energy practices, as well as reducing waste to zero. These guidelines should be applied at all stages from extraction and production to consumption and processing.

N. Boken, E. Olivetti, And J. Cullen, J. Potting and R. Lifset [17] identified four main features of circular economics:

industrial design where a new product should be designed with the subsequent option of reuse or recycling and resource for other products with minimal losses;

application of new innovative business models focused on cyclical production and resource consumption;

reverse cycles, minimal impact on the natural environment when meeting the needs of the population;

preference of reuse, repair, and modernization over creating new products.

The practical implementation of certain features of the circular economy is reflected in the regulatory documents that have been applied over the past decade in the most developed countries and EU Member States. Thus, in 2015 the European Commission adopted the first Circular Economy Action Plan, which (based on the 2019 report) was recognized as implemented. The most important results were attributed to a $6 \%$ increase in the number of jobs in circular economy-related sectors. In March 2020, a new action plan was adopted, its implementation will allow the EU to increase GDP by $0.5 \%$ and create additional 700 thousand new jobs [18]. According to the new action plan, the Global Alliance on Circular Economy and Resource Efficiency (GACERE) was established in February 2021, whose task is to provide global impetus to initiatives related to the transition to a circular economy of efficient use of resources and sustainable consumption and production. The Alliance consists of such countries as the EU, Canada, Japan, Chile, Colombia, Kenya, Morocco, New 
Zealand, Nigeria, Norway, Peru, Rwanda, South Africa. According to EU analysts, the introduction of resourceefficient production technologies at all levels of production chains will reduce industrial needs for raw materials by $17-24 \%$ by 2030 and reduce annual costs of enterprises by EUR 630 bln [19].

In addition to forecasts [20], it is advisable to take into account the actual data on the implementation of the circular economy, which is facilitated by the results of a thorough study of Eurostat analytical [21] data. A certain generalizing indicator was the cycle coefficient, the calculation results of which allow us to determine the share of materials obtained after processing in the total amount of resources used for production purposes. Thus, in 2019, the level of material reuse in the EU reached $11.9 \%$, which is 3.6 points more as compared to 2004 [22].

Eurostat also clarifies that the circulation rate is an order of magnitude lower than other indicators used to characterize the rate of transition to a circular economy. Thus, the recycling rate was about $56 \%$ in 2019 . This is due to the fact that not all materials can be returned as resources for further use. For example, this applies to food or fossil fuels burned for energy. If we study the dynamics and level of the cycle indicator, it is advisable to note its maximum positive level in the Netherlands $(28.5 \%)$ and critically low in Romania (1.5\%).

According to the State Statistics Service, Ukraine is characterized by the lack of unambiguous dynamics in the amount of waste generated with a fairly low processing rate. Thus, in $2019,0.23 \%$ of the garbage was burned as only one incinerator facility "Energia" (Kyiv) operates in our country (commissioned in 1987), is technically outdated and requires modernization. The total amount of waste accumulated in specially designated areas in 2019 amounted to 12,442,168.8 thous. tons [23].

For comparison, back in 2017 the European Commission took the initiative to close incinerators in favor of resource reuse through mandatory waste sorting. Today Germany has reached the level of $66 \%$ waste return as resources for reuse in production. Sweden uses not only its garbage, but also imports it from neighboring countries, for which the latter pay extra charges.

According to recent publication Ukraine has accumulated 36 bln tons waste of which 1.5 bln tons are hazardous waste. According to various sources, 4 to $7 \%$ of our country is littered with garbage [24]. This situation can be considered the result of an inefficient environmental protection policy where the main financial resources are focused on maintaining a system that favours waste storage versus processing. In addition to significant gaps regarding waste management at the state level, the official statistics indicate a low level of innovative activity of Ukrainian enterprises, in particular in terms of introducing low-waste and resource-saving technologies [23].

With $13.8 \%$ of innovation-oriented industrial enterprises in 2019 as few as 857 technologies were introduced that meet the principles of a circular economy, which is insufficient to switch to this model and close the gap between Ukraine and other countries.

The circular economy involves not only focusing on changes in production volumes, more efficient use of resources and waste management as a basis for creating new products, but also focusing on educating the population about reducing waste by individual households.

According to official statistics, the amount of waste in Ukraine is growing not only related to the activities of business entities, but also in the private sector, that is, the so-called household and similar waste (HSW), which is generated in the course of human activity in residential and non-residential buildings [23].

According to Eurostat [25], $225 \mathrm{mln}$ tons of municipal waste were generated in the EU in 2019, which amounts to $502 \mathrm{~kg}$ per person. In the context of the individual Member States, this figure was the highest in Denmark (844 kg), and the lowest in Romania (280 kg).

If we compare these figures with the State Statistics Service data, Ukraine currently shows an acceptable level of waste, but one should take into account two aspects: first, the difference in the assessment of the level of waste and the fact that there are a significant number of unauthorized landfills on the territory of Ukraine, which are not reflected in the official data; secondly, in 2019 as much as $239 \mathrm{~kg}$ of waste per person was recycled in the EU, including $134 \mathrm{~kg}$ incinerated, while in Ukraine as few as $4.7 \mathrm{~kg}$ of waste were recycled. Eurostat also provides data on a significant reduction in the amount of waste taken to landfills from $286 \mathrm{~kg}$ per person in 1995 to $120 \mathrm{~kg}$ in 2019 , while increasing the volume of waste itself. These figures strongly demonstrate the EU's focus on reducing the amount of waste accumulated in landfills by increasing processing intensity and the absence of significant positive developments in Ukraine.

Ukraine has approved the National Waste Management Strategy 2030 [26], accordance to which $15 \%$ and $50 \%$ of household waste should be processed by 2023 and 2030 respectively. In addition, 27 thousand unauthorized landfills should be eliminated by 2030 with the spread of household waste sorting ( $23 \%$ and $28 \%$ by 2023 and 2030 respectively).

While in Ukraine today we are mostly talking about declarative intentions without significant progress, the EU develops information support for wider application of the circular economy principles. According to the EU data [22] $67 \%(5.37 \mathrm{Gt})$ of raw materials are produced within the EU, and another $21 \%(1.73 \mathrm{Gt})$ are imported. 
The total processing capacity is $8.07 \mathrm{Gt}$ that includes 0.96 Gt of processed raw materials, which were used for the production of new finished products in the amount of $4.55 \mathrm{Gt}$. The data should become a reference point for Ukraine as a convincing proof of the economic feasibility of more active compliance with the principles of circular economics.

A separate important aspect that is particularly relevant for Ukraine today is that the circular economy contributes to the creation of additional jobs. Certain analytical data have already been provided for the EU, however concerning Ukraine, after overcoming the Covid-19 crisis, a significant increase in the number of migrant workers is expected. In this context a broader transition to a circular economy will help reduce the outflow of human resources from the country.

\section{DISCUSSION OF RESULTS}

The introduction of the circular economy is associated with a number of challenges, both theoretical and methodological, scientific in nature, in particular regarding the relationship and place of this formation in the paradigm of the "new economy" [27], in social existence [28], as well as purely applied aspects. After all Ukraine needs to take into account a fairly large number of the latter when moving from the development of strategic plans to tactical measures and further specifying each individual area of the national economy:

countries with raw material-oriented economies in the first stages suffer losses as a result of reduced demand for natural resources due to their more efficient use and the spread of waste processing practices;

the transition to a circular economy cannot be rapid as it requires significant modernization of existing production facilities to reduce resource and energy intensity;

the large-scale transition requires the establishment of appropriate infrastructure, which is difficult to implement without appropriate legislative changes that provide for the support of business structures and the implementation of outreach campaigns among the population;

reuse is more efficient versus recycling, because during this process there is not only a loss of some resources, but also a deterioration in their quality composition, so ensuring the possibility of repair and modernization of each product becomes a priority;

since raw material prices show volatility in global markets, there is a situation when the resources obtained after processing will be uncompetitive.

\section{CONCLUSIONS}

Ukraine declares focus on the transition to the principles of a circular economy, although official statistical data indicate the lack of significant progress, in particular in terms of waste management and low innovative activity of business structures regarding the introduction of resource- and energy-saving technologies.

In order to maintain measures that comply with the principles of circular economics, it is important to use more active economic instruments, one of which is environmental taxes. Despite the fact that the content of most of such taxes in Ukraine corresponds to those paid in the EU, their level is lower. In most EU countries, revenues from environmental taxes are higher than environmental protection expenditures, which allows for more efficient use of revenues, in particular in the form of capital investments. Another knotty issue is the conditions for public procurement where the main criterion is a lower price, which does not allow producers of environmentally friendly products to compete on equal terms.

The efficiency of implementing the circular economy principles requires a comprehensive multi-level approach, that is, at the state level, in the conditions of an individual enterprise and in the minds of individual citizens. Only synchronous progress will allow Ukraine, despite the need for significant transformations and real challenges, to catch up with the leaders of economic development.

\section{REFERENCES}

[1] Boulding, K. (1966), The Economics of the Coming Spaceship Earth, Resources for the Future, 14 p.

[2] Pearce, D. and Turner, R. (1992), Economy of natural resources and environment, Dialog-MGU.

[3] Turner, R. K. (1993), Sustainability: principles and practice, Belhaven Press.

[4] Kulczycka, J. (2019), Definitions and their interpretations. In J. Kulczycka (Ed.), Circular economy in politics and research, IGSMiE PAN Publishing House, pp. 9-15, available at: https://circulareconomy.europa.eu/platform/sites/d efault/files/the_circular_econom y_in_policy_and_scientific_research.pdf

[5] Korystin, O.Ye. (2020), Chapter 4. State Legal Police of Scientific Prediction. Public administration in the digital economy, monograph, Tallinn, Scientific Center of Innovative Researches OU, DOI: 10.36690 PADE

[6] Dajian Zhu (2014), China's policies and instruments for developing the circular economy, Europe's World, June 15.

[7] Odji, Ebenezer (2019), "Graphic Design Principles and Theories Application in Rendering Aesthetic and Functional Installations for Improved 
Environmental Sustainability and Development", International Journal of Engineering and Manufacturing, vol. 9, no. 1, pp. 21-37, DOI: $10.5815 /$ ijem.2019.01.03

[8] Mehran Junejo, Asif Ali Laghari, Awais Khan Jumani, Shahid Karim and Mansoor Ahmed Khuhro (2020), " Quality of Experience Assessment of Banking Service", International Journal of Information Engineering and Electronic Business, vol.12, no. 6, pp. 39-50, DOI: $10.5815 /$ ijieeb.2020.06.04

[9] Circular Economy / Cradle to Cradle, Drees \& Sommer, available at: https://www.dreso.com/de/dreso/ nachhaltig/cradle-to-cradle

[10] Srinivas, H. (2015), Industrial Ecology, Sustainable Development: Concepts, available at: https://www.gdrc.org/ sustdev/concepts/16-1eco.html

[11] Sustainable Blue Economy, European Commission, available at: https://ec.europa.eu/oceans-andfisheries/ocean/ blue-economy/sustainable-blueeconomy_en

[12] Unruh, G. (2018), Circular Economy, 3D Printing, and the Biosphere Rules, California Management Review, available at: https://journals.sagepub.com/doi/abs/ 10.1177/0008125618759684? journalCode $=\mathrm{cmra}$

[13] Chen Demin (2004), "Core of recycling economy is to use resources circularly@, China Population, Resources and Environment, vol. 14 (2), pp. 12-15.

[14] Towards a Circular Economy: Business Rationale For An Accelerated Transition (2015), Ellen MacArthur Foundation, available at: https://www.ellenmacarthurfoundation.org/assets/ downloads/TCE_Ellen-MacArthur-Foundation-9Dec-2015.pdf

[15] About Sustainable Development Goals for Ukraine until 2030: Decree of President of Ukraine № 722/2019 (2019, September 09), available at: https://zakon.rada.gov.ua/laws/show/722/2019 \#Text

[16] Strategy of low-carbon development of Ukraine until 2050 (2018), Ministry of energy and environment protection of Ukraine, available at: https://mepr.gov.ua/files/docs/Proekt/LEDS_ua_la st.pdf

[17] Bocken, N.M.P. Olivetti, E.A. Cullen, J.M. Potting, J. and Lifset, R. (2017), "Taking the Circularity to the Next Level: A Special Issue on the Circular Economy", Journal of Industrial Ecology, available http://publications.eng.cam.ac.uk/907388/
[18] Circular Economy Action Plan (2020), European Commission, available at: https://ec.europa.eu/environment/ circulareconomy/pdf/ new_circular_economy_action_plan.pdf

[19] European Commission (2018), Circular Economy: New rules will make EU the global front-runner in waste management and recycling [Press release], available at: http://europa.eu/rapid/pressrelease_IP-18-3846_en.htm

[20] Korystin, Oleksandr and Svyrydiuk, Nataliia (2021), "Activities of Illegal Weapons Criminal Component of Hybrid Threats", Proceedings of the International Conference on Economics, Law and Education Research (ELER 2021), vol. 170, 22 March, pp. 86-91, DOI: 10.2991/aebmr.k.210320.016

[21] Pubudu K. Hitigala Kaluarachchilage, Champike Attanayake, Sasith Rajasooriya and Chris P. Tsokos (2020), "An Analytical Approach to Assess and Compare the Vulnerability Risk of Operating Systems", International Journal of Computer Network and Information Security, vol. 12, no. 2, pp.1-10, DOI: 10.5815/ijcnis.2020.02.01

[22] Material flows in the circular economy (2021), Eurostat, available at: https://ec.europa.eu/eurostat/statisticsexplained/index.php?title=Material_flows_in_the circular_economy\#Sankey_diagram_of_material_f lows

[23] Analytical data, State Statistical Service of Ukraine, available at: http://www.ukrstat.gov.ua/

[24] Shapoval, N. (2018), A hope for refinement. How Ukraine could overcome the refuse, $\mathrm{LB}$, available at:

https://lb.ua/society/2018/04/28/395698_nadiya_o chishchennya_yak_ukraina_mozhe.html

[25] Half a tonne of municipal waste generated per person in the EU (2021), Eurostat, available at: https://ec.europa.eu/eurostat/web/productseurostat-news/-/ddn-20210216-1

[26] About approval of National Strategy of Waste Management in Ukraine until 2030: Decree of Cabinet of Ministers of Ukraine № 820-p. (2017, November 18), available at: https://zakon.rada.gov.ua/laws/ show/820-2017$\% \mathrm{D} 1 \% 80 \#$ Text

[27] Kotlyarevskyy, Ya.V. Melnychenko, A.A. Ivanytska, O.I. Semenyuk, E.P. Kniaziev, S.I. and Melnikov, A.V. (2020), "New Economy: Evolution of Forms and Research Methodology", Sci. innov, vol. 16 (1), pp. 15-30, DOI: 10.15407/ scine16.01.015

[28] Ecologization of society: social role and modelling. (2012), Ukrainian Academy of Printing. 